\title{
Increased Relapse Activity for Multiple Sclerosis Natalizumab Users Who Become Nonpersistent: A Retrospective Study
}

\author{
R. Brett McQueen, PhD; Terrie Livingston, PharmD; Timothy Vollmer, MD; John Corboy, MD; \\ Brieana Buckley, PharmD; Richard Read Allen, MS; Kavita Nair, PhD; and Jonathan D. Campbell, PhD
}

\begin{abstract}
BACKGROUND: Natalizumab disease-modifying therapy for relapsingremitting multiple sclerosis (MS) is efficacious in randomized controlled trials. Few studies have estimated the association between real-world natalizumab persistence behavior and relapse-related outcomes.

OBJECTIVES: To (a) examine the impact of using natalizumab consistently (i.e., persistent) on relapse-related outcomes as compared with transitioning to inconsistent natalizumab use (i.e., nonpersistent) and (b) examine the impact of other treatment patterns on relapse-related outcomes for those who initiated natalizumab.
\end{abstract}

METHODS: Using the IMS PharMetrics Plus claims database (years 20062012), we identified MS subjects who initiated natalizumab (no natalizumab claims in year prior) and had at least 2 years of follow-up. Persistence in annual follow-up periods was defined as no 90-day or greater gap in natalizumab therapy. Relapse was an MS-related hospitalization or outpatient visit with intravenous or oral steroid burst claim within 7 days. Analyses compared observations based on changes in natalizumab persistence and natalizumab nonpersistence status from 1 year to the next (e.g., transitioning from persistent to nonpersistent), estimating differences in mean annual relapses and mean annual relapse-related costs.

RESULTS: A total of 2,407 natalizumab initiators had at least 2 years of follow-up, yielding 4,770 year-to-year natalizumab treatment patterns where each subject contributed 1, 2, or 3 year-to-year treatment patterns. In the year prior, 3,187 treatment patterns were persistent; $731(22.9 \%)$ of these transitioned to nonpersistence. The remaining 1,583 treatment patterns were nonpersistent in the year prior; $132(8.3 \%)$ of these transitioned to persistence. Persistent to nonpersistent treatment patterns were associated with a mean relapse-rate increase of $0.23(95 \% \mathrm{Cl}=0.12,0.35)$, and a mean increase in relapse-related costs of $\$ 1,346(95 \% \mathrm{Cl}=\$ 97, \$ 2,595)$. Nonpersistent to persistent treatment patterns were associated with a mean relapse-rate decrease of $-0.15(95 \% \mathrm{Cl}=-0.32,0.017)$ and a mean decrease in relapse-related costs of $-\$ 1,369(95 \% \mathrm{Cl}=-\$ 2,761, \$ 23)$.

CONCLUSIONS: Findings suggest that real-world persistent natalizumab users who become nonpersistent have statistically significant increases in annual relapses and relapse-related costs. Those who transition from nonpersistent to persistent have nonsignificant reductions in relapses and their associated costs.

J Manag Care Spec Pharm. 2015;21(3):210-18

Copyright $\odot 2015$, Academy of Managed Care Pharmacy. All rights reserved.

\section{What is already known about this subject}

Previous clinical trial studies on natalizumab use in multiple sclerosis (MS) patients have provided evidence that nonpersistence, through switching or discontinuation from natalizumab, has been associated with a return of disease activity.

The use of natalizumab as a second-line agent (i.e., switching to natalizumab from a first-line agent) has been effective in improving outcomes for MS patients.

\section{What this study adds}

Findings suggest subjects who were persistent on natalizumab prior to a change in treatment without natalizumab (e.g., switch or discontinue) had significant increases in relapses and relapserelated costs.

Subjects who were not persistent on natalizumab prior to a change in treatment with persistent use of natalizumab had nonsignificant reductions in relapses and relapse-related costs.

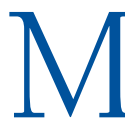
ultiple sclerosis (MS) is a chronic and debilitating disorder of the central nervous system. Recent research has estimated MS prevalence in the United States at approximately 570,000. ${ }^{1}$ MS imposes an economic burden on patients with annual medical direct costs of over $\$ 20,000$ higher than individuals without MS. ${ }^{1}$ MS is characterized by acute and unpredictable attacks known as relapses, followed by a period of partial or full recovery of symptoms known as remission. ${ }^{2}$ Disease symptoms such as difficulty with balance, memory problems, poor vision, and speech problems may become progressively worse over time. Approximately $85 \%$ of individuals with MS are initially diagnosed with the relapsingremitting (RRMS) form of the disease. ${ }^{3}$ Most individuals with RRMS will then transition to secondary progressive MS with a median time to transition of 15 years postdiagnosis. ${ }^{4}$ A small percentage of people are diagnosed with primary progressive MS, characterized by steadily worsening neurologic function from their initial diagnosis.

The goal of disease-modifying therapies (DMTs) for the treatment of MS is to prevent or reduce the risk of relapses and slow disease progression. DMTs such as interferons (IFNs) and glatiramer acetate (GA) have been used as first-line agents for the treatment of RRMS. ${ }^{5}$ However, some patients do not 


\section{FIGURE 1 Sample Selection Flowchart}

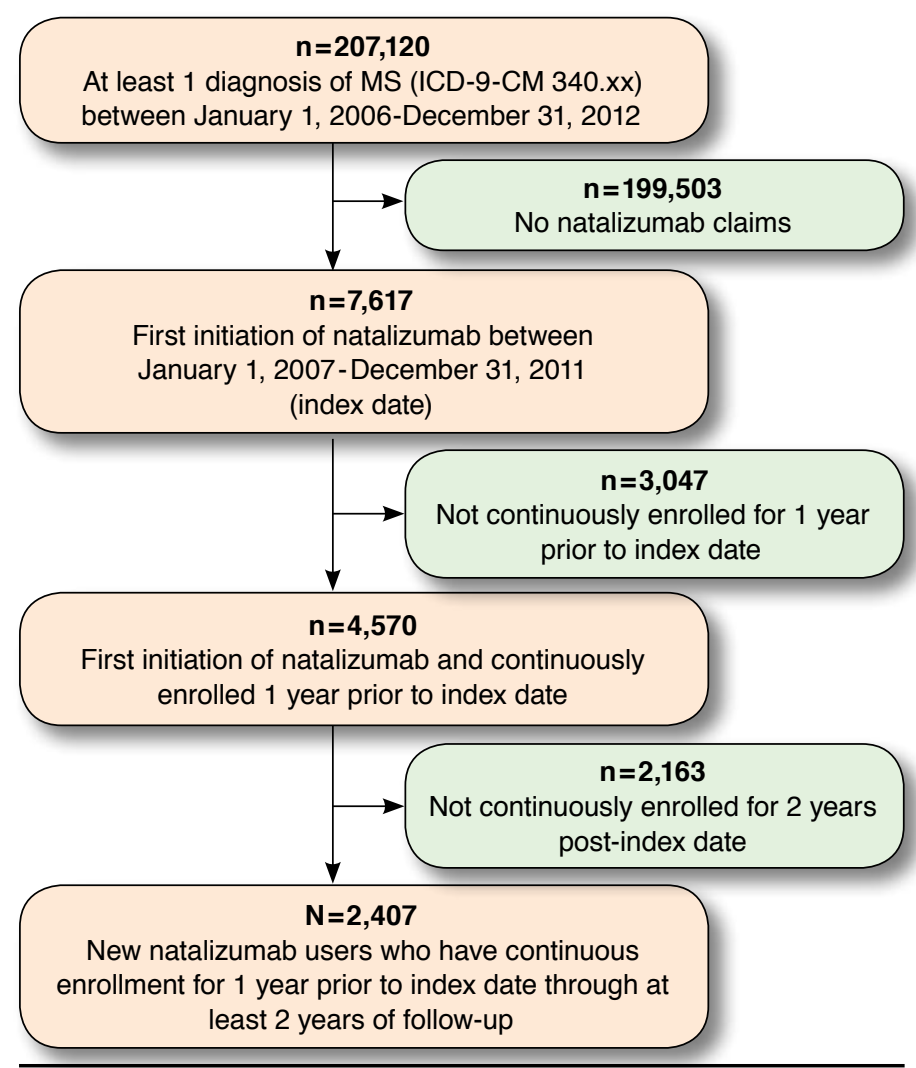

ICD-9-CM = International Classification of Diseases, Ninth Revision, Clinical Modification; $M S=$ multiple sclerosis

respond to treatment. Reasons for switching or discontinuing include tolerability (e.g., skin reaction, injection site reactions, and flu-like symptoms); safety (e.g., allergic reaction, elevations in liver enzymes, depression, and immediate postinjection reaction); lack of efficacy (e.g., no perceived benefit); and burden (e.g., injection frequency). ${ }^{6-8}$ To maximize the benefits of DMTs, MS patients must be persistent and adherent to their prescribed therapies. Persistence is a measurement of medication behavior and has been defined as "the duration of time from initiation to discontinuation of a therapy."

Natalizumab (Tysabri, Biogen Idec) is approved as monotherapy for the treatment of patients with relapsing forms of MS to delay physical disability and reduce relapse activity. ${ }^{10}$ Data from clinical studies have provided evidence that nonpersistence, through switching or discontinuation from natalizumab, has been associated with a return of disease activity. ${ }^{11,12}$ Additionally, studies have shown that the use of natalizumab as a second-line agent (i.e., switching to natalizumab from a first-line agent) has been effective in improving outcomes for MS patients. ${ }^{13-15}$
Previous studies have measured persistence but have not linked persistence behavior to outcomes such as relapses or relapse-related costs. ${ }^{16-20}$ Some studies have measured persistence and linked behavior to relapse outcomes, ${ }^{21-28}$ however, few have focused specifically on natalizumab, ${ }^{13-15,24,29}$ and of those studies, none have focused on natalizumab treatment patterns and the resulting impact on relapse-related outcomes in a large U.S. commercially insured population.

Our objectives in this study were to use a large longitudinal claims database to (a) estimate the change in treatment patterns based on persistence status, with a primary treatment pattern identified as the transition from natalizumab persistent to natalizumab nonpersistent, and (b) estimate the change in relapses and relapse-related costs associated with the change in treatment patterns.

\section{Methods}

\section{Data Source}

This retrospective study utilized the IMS PharMetrics Plus claims database, a nationwide U.S. database of longitudinal subject-level health care utilization and expenditure data for commercially insured enrollees. PharMetrics Plus combines data from Blue Health Intelligence for a total of 150 million covered lives; approximately 87 million of those covered lives have both pharmacy and medical coverage across all years. The database includes prescribed medications, diagnoses and procedures, medical and pharmacy costs, demographics, and payer and provider information. International Classification of Diseases, Ninth Revision, Clinical Modification (ICD-9-CM) diagnosis codes were used to identify individuals with MS (ICD9-CM 340.xx). Medical claims were identified using Current Procedural Terminology, Version 4 (CPT-4) procedure codes, Healthcare Common Procedure Coding System (HCPCS) procedure codes, and (ICD-9-CM) procedure codes. National Drug Code numbers 59075-730-15 and 64406-008-01 and HCPCS code J2323 were used to identify natalizumab claims.

\section{Sample Selection}

Figure 1 displays the sample selection process. The study subjects were selected from commercially insured members who initiated natalizumab and had at least 1 previous MS diagnosis. Specifically, inclusion criteria included (a) first initiation of natalizumab between January 1, 2006, and December 31, 2012 (defined as the index date); (b) at least 1 MS diagnosis (ICD-9-CM 340.xx) during the 12-month baseline period prior to index date; (c) no natalizumab claims during the 12-month baseline period prior to index date; and (d) at least 2 years of continuous enrollment post-index date. Each subject provided at least 3 years of observations (baseline or year 0, follow-up year 1 , follow-up year 2) and up to 5 years of observations (baseline or year 0 , follow-up year 1 , follow-up year 2 , followup year 3, follow-up year 4). 


\section{Measures}

Demographics. Subject demographics included age, gender, region, health plan type, and baseline health care utilization. Proxies for baseline MS disease severity were estimated using subject-level counts of MS-related symptoms, mobility status, and the Charlson Comorbidity Index (CCI) score adapted for claims-based analyses. ${ }^{30-32}$ Baseline MS-related symptoms were captured using ICD-9-CM codes and coded as binary indicator variables. These symptoms were categorized based on previous work by Curkendall et al. (2011) $)^{33}$ and included visual symptoms, movement disorders, facial neuralgia, dizziness, chronic fatigue, paralysis, headache, muscle symptoms, speech symptoms, and disturbance of skin sensation. Mobility status was captured using CPT-4 and HCPCS codes for wheelchairs and walking aids.

Treatment Patterns. The primary explanatory variable for relapses and relapse-related costs was the change from natalizumab persistence to nonpersistence over the same 2-year period. Persistence in annual follow-up periods was defined as no gap in natalizumab claims greater than 90 days, which is similar to other claims-based studies. ${ }^{16,23}$ Nonpersistence was defined as switched to another DMT (i.e., use of 2 or more DMTs within a year and no 90-day or greater gap on the final DMT used at the end of the year); discontinued natalizumab (i.e., no natalizumab or other DMT claim for at least the last 90-day period in the year following natalizumab initiation); or had at least one 90-day or greater gap in natalizumab claims during a calendar year after natalizumab initiation with subsequent natalizumab or other DMT use that did not fall into the switch definition.

Previous claims analyses have estimated outcomes separately for those who switch or discontinue, rather than merging these groups into a larger category of nonpersistence. ${ }^{16,23}$ There were 2 main reasons that we chose to merge switching and discontinuation into the category of nonpersistence: (1) there was little statistical difference in baseline characteristics between the subcategories switch, discontinue, and a 90-day or greater gap following natalizumab initiation (Appendix A, available in online article); and (2) the goal of this analysis was to examine the global impact of using natalizumab consistently as compared with inconsistent natalizumab use, even if that involved switching to another therapy or discontinuing. Merging these groups expanded the traditional definition of nonpersistence to include not only gaps in therapy, but also the clinical failure or intolerability of natalizumab. Those who may have switched to another therapy would be grouped into natalizumab nonpersistence.

While the primary analysis focused on the pattern of natalizumab persistence to nonpersistence, we also grouped and estimated additional patterns of persistence and split these observations into 4 mutually exclusive and exhaustive groups for each 2-year period post-index date. Similar to annual change in outcomes, subjects contributed a minimum of 1 persistence treatment pattern over 2 years and a maximum of 3 persistence treatment patterns over 4 years after natalizumab initiation. During each year prior to and after observation, a subject could be persistent for 2 years (i.e., persistent to persistent); persistent for the year prior, then nonpersistent during the year after (i.e., persistent to nonpersistent); nonpersistent during the year prior, then persistent during the year after (i.e., nonpersistent to persistent); and nonpersistent during both years prior and after (i.e., nonpersistent to nonpersistent).

Relapse Outcomes. Proxies were used to define relapse outcomes. Relapse was defined as an MS-related hospitalization or MS-related emergency or outpatient visit with intravenous or oral steroid burst claim (methylprednisolone, prednisolone, prednisone, or adrenocorticotropic hormone) within 7 days. ${ }^{34,35}$ Relapse-related cost was defined as the payer and subject paid claims for the associated relapse-related events. All costs were inflated to 2012 U.S. dollars using an average of the medical inflation rate over the study period.

The unit of analysis was a within person year-to-year pair of observations from each contributing plan member. The outcomes of interest were the time-varying change in relapses and relapse-related costs following initiation of natalizumab. Change in relapse variables were defined the following:

\section{$\triangle$ Annual relapse outcomes $=$ year post relapse outcomes - year prior relapse outcomes}

Annual relapse outcomes were evaluated at years 1, 2, 3, and 4 post-index date. Subjects contributed a minimum of 1 change in relapse-outcome observation (2 years of follow-up) and a maximum of 3 changes in relapse-outcome observations (4 years of follow-up). Each subject had at least 1 "year prior" outcome and 1 "year post" outcome. For example, a subject with 2 follow-up years post-index date would have 1 change in relapse outcome (change from year 1 post-index date to year 2). Similarly, a subject with 3 follow-up years would have 2 changes in relapse outcomes (change from year 1 post-index date to year 2 , and change from year 2 post-index date to year 3).

Statistical Analysis. Univariate analysis was used to compare baseline demographics and MS-related measures of disease severity between those who were persistent on natalizumab during the first year post-index date and those who were not persistent in the first year post-index date. We used chisquared distributional tests for categorical variables and independent sample t-tests for continuous variables.

The change in relapses and relapse-related costs were estimated within each treatment pattern group using linear regression with cluster-robust standard errors to account for the within subject correlation over time. ${ }^{36,37}$ This method utilizes the longitudinal nature of the data by analyzing within patient changes in treatment patterns on changes in relapse outcomes. Cluster-robust standard errors allow for intrasubject correlation 
by relaxing the assumption of independent observations. That is, the individual subjects themselves are independent but the observations within subjects are not independent. In the multivariable model, we adjusted for prior DMT use (any claim for interferon beta la [intramuscular], interferon beta la [subcutaneous], interferon beta $\mathrm{lb}$ [subcutaneous], or glatiramer acetate during baseline period), baseline $\mathrm{CCI}$, gender, baseline age, and region of the United States. The estimates are presented as baseline outcomes with the change and 95\% confidence interval $[\mathrm{CI}]$ in annualized relapse rates and relapse-related costs within each persistent group. We also tested whether the changes in relapse outcomes for each persistent group were different from the reference group persistent to persistent.

Relapse counts and relapse-related cost data can often be non-normal and skewed. However, after differencing both variables, histograms and detailed summary statistics showed both variables were normally distributed, indicating the appropriate use of linear regression. Analyses were performed using STATA version 12 (StataCorp, College Station, TX).

Sensitivity Analyses. We performed separate subgroup analyses for those subjects contributing at least 2 years, at least 3 years, and at least 4 years of observations to analyze if differences in the number of contributing years from subjects altered the findings. Additionally, the base analysis was performed with inclusion of all baseline MS-related symptom variables regardless of significance level. Concern over inclusion of these variables in the main analysis was due to collinearity between the MS-related symptom variables and CCI, since both are calculated from individual ICD-9-CM coding. Residual plots were used to analyze normality of residuals, assumption of constant variance, and any outliers. We removed any extreme outliers and examined the impact on the results.

\section{Results}

Table 1 presents the demographic and clinical characteristics before natalizumab initiation for the overall population, for those who were persistent in the initiation year, and for those that were not persistent in the initiation year. A total of 2,407 natalizumab initiators had at least 2 years of follow-up data. The majority of the subjects were females (74\%), and the sample was largely insured in preferred provider networks (76\%). Seventy-five percent of patients were persistent during the first year post-index date, with prior DMT use significantly different between those persistent during the initiation year and those nonpersistent during the initiation year $(P<0.001)$. Sixty-two percent of patients attempted at least $1 \mathrm{DMT}$ prior to initiating natalizumab.

\section{Treatment Patterns}

Among the 4 persistence pattern groups identified, there were 4,770 treatment patterns where each subject contributed 1, 2, or 3 year-to-year natalizumab transitions (Table 2). From the 3,187 treatment patterns that were persistent in the year prior,
731 (22.9\%) of those transitioned to nonpersistence in the year after, and 2,456 stayed persistent in the year after. The remaining 1,583 treatment patterns were nonpersistent in the year prior; 132 (8.3\%) of these transitioned to persistence; and 1,451 (92\%) stayed nonpersistent in the year after.

\section{Relapse Outcomes}

Table 3 presents the regression-adjusted relapse rate and relapse-related costs in the year prior to persistence transition for each 1 of the 4 persistence transition groups. On average, relapse rate and relapse-related costs in the year prior to treatment transition were highest for those who were nonpersistent in the year prior and remained nonpersistent (annualized relapse rate $=0.67,95 \% \mathrm{CI}=0.52,0.81$; relapse-related cost $=\$ 3,816,95 \% \mathrm{CI}=\$ 3,029, \$ 4,602)$. The lowest relapse rate and relapse-related cost in the year prior to treatment transition were for those patients who were persistent and remained persistent (annualized relapse rate $=0.28,95 \% \mathrm{CI}=0.24,0.32$; relapse-related cost $=\$ 1,289,95 \% \mathrm{CI}=\$ 988, \$ 1,590)$.

Figure 2 and Figure 3 display the respective adjusted longitudinal linear regression results for relapse rates and relapserelated costs within each of the 4 possible persistence transition patterns. There was a statistically significant $(P<0.001)$ within-group increase in relapse rates of $0.23(95 \% \mathrm{CI}=0.12$, $0.35)$ for transitions from persistent to nonpersistent. In percentage terms, transitioning from persistent to nonpersistent was associated with a 52\% increase in relapse rates. There was a decrease in relapse rates of $-0.15(95 \% \mathrm{CI}=-0.32,0.017)$ for those who transitioned from nonpersistent to persistent, but this change was significant at $P=0.08$. Transitioning from nonpersistent to persistent was associated with a 32\% decrease in relapse rates. There was also a small decrease in relapse rates of $12 \%$ for those transitioning from nonpersistent to nonpersistent $(-0.08,95 \% \mathrm{CI}=-0.16,-0.01)$.

Relapse-related costs in Figure 3 showed a similar pattern. Within-group increases in relapse-related costs were significant for transitions from persistent to nonpersistent $(\$ 1,346$, $95 \% \mathrm{CI}=\$ 97, \$ 2,595)$. In percentage terms, transitioning from persistent to nonpersistent was associated with a $58 \%$ increase in relapse-related costs. There was a decrease in relapse-related costs for those who transitioned from nonpersistent to persistent $(-\$ 1,369,95 \% C I=-\$ 2,761, \$ 23)$, but this within-group change was also only significant at $P=0.054$. Transitioning from nonpersistent to persistent was associated with a $56 \%$ decrease in relapse-related costs.

Differences between groups were also tested for changes in relapses and relapse-related costs. Compared with the persistent to persistent reference group, the relapse rate $(0.23$ vs. - 0.01 ) and relapse-related cost changes ( $\$ 1,346$ vs. $-\$ 130)$ for persistent to nonpersistent were significantly different at $P=0.045$; the relapse-related cost change for nonpersistent to persistent was also significantly different at $P=0.039(-\$ 1,369$ vs. $-\$ 130)$. 


\begin{tabular}{|c|c|c|c|c|c|c|c|}
\hline & \multicolumn{2}{|c|}{ Overall } & \multicolumn{2}{|c|}{$\begin{array}{l}\text { Persistent in } \\
\text { Initiation Year }\end{array}$} & \multicolumn{2}{|c|}{$\begin{array}{l}\text { Nonpersistent in } \\
\text { Initiation Year }\end{array}$} & \multirow[b]{2}{*}{$P$ Value ${ }^{a}$} \\
\hline & $\mathrm{N}$ & $\%$ & $\mathrm{~N}$ & $\%$ & $\mathrm{~N}$ & $\%$ & \\
\hline Total & 2,407 & - & 1,800 & 74.78 & 607 & 25.22 & \\
\hline Gender & & & & & & & 0.259 \\
\hline Male & 621 & 25.80 & 450 & 25.00 & 171 & 28.17 & \\
\hline Female & 1,785 & 74.16 & 1,349 & 74.94 & 436 & 71.83 & \\
\hline Age group & & & & & & & 0.923 \\
\hline $0-35$ & 404 & 16.78 & 297 & 16.50 & 107 & 17.63 & \\
\hline $36-44$ & 745 & 30.95 & 558 & 31.00 & 187 & 30.81 & \\
\hline $45-54$ & 843 & 35.02 & 635 & 35.28 & 208 & 34.27 & \\
\hline $55+$ & 415 & 17.24 & 310 & 17.22 & 105 & 17.30 & \\
\hline Payer type & & & & & & & 0.239 \\
\hline Commercial & 1,504 & 62.48 & 1,135 & 63.06 & 369 & 60.79 & \\
\hline Medicaid or Medicare & 42 & 1.74 & 29 & 1.61 & 13 & 2.14 & \\
\hline Self-insured & 861 & 35.77 & 636 & 35.33 & 225 & 37.07 & \\
\hline Insurance type & & & & & & & 0.498 \\
\hline Health maintenance organization & 288 & 11.97 & 213 & 11.83 & 75 & 12.36 & \\
\hline Indemnity & 100 & 4.15 & 75 & 4.17 & 25 & 4.12 & \\
\hline Preferred provider network & 1,831 & 76.07 & 1,382 & 76.78 & 449 & 73.97 & \\
\hline Point of service & 154 & 6.40 & 105 & 5.83 & 49 & 8.07 & \\
\hline Consumer driven & 13 & 0.54 & 9 & 0.50 & 4 & 0.66 & \\
\hline Unknown & 21 & 0.87 & 16 & 0.89 & 5 & 0.82 & \\
\hline Region & & & & & & & 0.216 \\
\hline East & 743 & 30.87 & 557 & 30.94 & 186 & 30.64 & \\
\hline Midwest & 716 & 29.75 & 551 & 30.61 & 165 & 27.18 & \\
\hline South & 696 & 28.92 & 502 & 27.89 & 194 & 31.96 & \\
\hline West & 252 & 10.47 & 190 & 10.56 & 62 & 10.21 & \\
\hline \multicolumn{8}{|l|}{ MS-related symptomsb } \\
\hline Visual & 454 & 18.86 & 326 & 18.11 & 128 & 21.09 & 0.105 \\
\hline Movement disorders & 662 & 27.50 & 507 & 28.17 & 155 & 25.54 & 0.209 \\
\hline Facial neuralgia & 52 & 2.16 & 35 & 1.94 & 17 & 2.80 & 0.210 \\
\hline Dizziness & 220 & 9.14 & 157 & 8.72 & 63 & 10.38 & 0.221 \\
\hline Fatigue & 52 & 2.16 & 38 & 2.11 & 14 & 2.31 & 0.775 \\
\hline Paralysis & 111 & 4.61 & 84 & 4.67 & 27 & 4.45 & 0.824 \\
\hline Headache & 33 & 1.37 & 25 & 1.39 & 8 & 1.32 & 0.897 \\
\hline Muscle & 245 & 10.18 & 178 & 9.89 & 67 & 11.04 & 0.418 \\
\hline Speech & 42 & 1.74 & 31 & 1.72 & 11 & 1.81 & 0.884 \\
\hline Skin disturbance & 432 & 17.95 & 319 & 17.72 & 113 & 18.62 & 0.620 \\
\hline \multicolumn{8}{|l|}{ Movement aidsc ${ }^{c}$} \\
\hline Walker & 80 & 3.32 & 64 & 3.56 & 16 & 2.64 & 0.274 \\
\hline Wheelchair & 77 & 3.20 & 21 & 1.17 & 56 & 9.23 & 0.673 \\
\hline Prior DMT use (yes) ${ }^{\mathrm{d}}$ & 1,426 & 59.24 & 1,111 & 61.72 & 315 & 51.89 & $<0.001$ \\
\hline Charlson Comorbidity Index (mean, SD) & 3.43 & 1.85 & 3.41 & 1.84 & 3.48 & 1.91 & 0.467 \\
\hline Relapse count & 0.57 & 1.14 & 0.55 & 1.09 & 0.62 & 1.27 & 0.239 \\
\hline \multicolumn{8}{|c|}{ 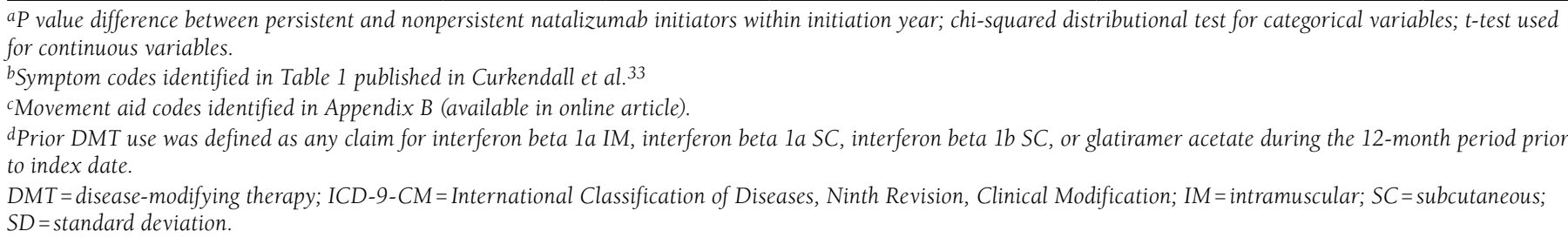 } \\
\hline
\end{tabular}




\begin{tabular}{|c|c|c|c|c|}
\hline & & $\begin{array}{l}\text { uency and } \\
\text { tment Patter } \\
\text { ators with at } \\
\text { w-up Data }\end{array}$ & $\begin{array}{l}\text { ercentage } \\
\text { hs for Nata } \\
\text { Least } 2 \text { Yea } \\
N=2,407 \text { ) }\end{array}$ & $\begin{array}{l}\text { nab } \\
f\end{array}$ \\
\hline & & $\begin{array}{c}\text { Nonpersistent } \\
\text { in Year Post }\end{array}$ & $\begin{array}{c}\text { Persistent in } \\
\text { Year Post }\end{array}$ & Total \\
\hline Nonpe & Yea & & & \\
\hline & $\mathrm{n}$ & 1,451 & 132 & 1,583 \\
\hline & $\%$ & 91.66 & 8.34 & 100.0 \\
\hline Persis & $\mathrm{Pr}$ & & & \\
\hline & $\mathrm{n}$ & 731 & 2,456 & 3,187 \\
\hline & $\%$ & 22.94 & 77.06 & 100.0 \\
\hline Total & & & & \\
\hline & $\mathrm{n}$ & 2,182 & 2,588 & 4,770 \\
\hline & $\%$ & 45.74 & 54.26 & 100.0 \\
\hline
\end{tabular}

Note: $n$ equals the number of year-to-year treatment patterns; \% equals the percentage of total treatment patterns based on prior year.

\begin{tabular}{|c|c|c|}
\hline & $\begin{array}{c}\text { Nonpersistent in } \\
\text { Year Post }\end{array}$ & $\begin{array}{l}\text { Persistent in } \\
\text { Year Post }\end{array}$ \\
\hline Nonpersistent in Year Prior & $\mathrm{n}=1,451$ & $\mathrm{n}=132$ \\
\hline $\begin{array}{l}\text { Annual number of relapses } \\
\text { in year prior }\end{array}$ & $\begin{array}{c}0.67^{\mathrm{a}} \\
(0.52,0.81)\end{array}$ & $\begin{array}{c}0.47 \\
(0.27,0.67)\end{array}$ \\
\hline $\begin{array}{l}\text { Annual relapse cost in } \\
\text { year prior }(\$)\end{array}$ & $\begin{array}{c}3,816^{\mathrm{a}} \\
(3,029,4,602)\end{array}$ & $\begin{array}{c}2,062 \\
(855,3,269)\end{array}$ \\
\hline Persistent in Year Prior & $\mathrm{n}=731$ & $\mathrm{n}=2,456$ \\
\hline $\begin{array}{l}\text { Annual number of relapses } \\
\text { in year prior }\end{array}$ & $\begin{array}{c}0.45^{\mathrm{a}} \\
(0.37,0.54) \\
\end{array}$ & $\begin{array}{c}0.28 \\
(0.24,0.32) \\
\end{array}$ \\
\hline $\begin{array}{l}\text { Annual relapse cost in } \\
\text { year prior (\$) }\end{array}$ & $\begin{array}{c}2,645^{a} \\
(1,753,3,537) \\
\end{array}$ & $\begin{array}{c}1,289 \\
(988,1,590) \\
\end{array}$ \\
\hline \multicolumn{3}{|c|}{$\begin{array}{l}\text { Note: Data are means }(95 \% \text { CI) in prior year. Costs in } 2012 \text { U.S. dollars. } \\
\text { a Significant at } P<0.05 \text { when compared with reference group persistent in year prior } \\
\text { and year post. } \\
C I=\text { confidence interval. }\end{array}$} \\
\hline
\end{tabular}

\section{Sensitivity Analyses}

Similar results were found when stratifying the population by contribution of observations. Specifically, the persistent to nonpersistent change in mean relapse (0.23) was positive and significant for all analyses including those subjects contributing at least 2 years, at least 3 years, and at least 4 years. Additionally, findings were consistent with those presented in figures 2 and 3 when including all baseline MS-related symptom variables. The main results presented do not include 1 extreme outlier found in the data.

\section{Discussion}

In this observational study, we found significant and clinically meaningful increases in relapse counts and relapse-related costs for natalizumab transitions from persistent to nonpersistent. Downward nonsignificant changes in relapse outcomes for natalizumab transitions from nonpersistent to persistent were also observed. Findings suggest subjects who were persistent on natalizumab prior to a change in treatment without natalizumab (e.g., switch or discontinue) had significant increases in relapses and relapse-related costs. Alternatively, subjects who were not persistent on natalizumab prior to a change in treatment with persistent use of natalizumab had nonsignificant reductions in relapses and relapse-related costs. This study adds to previous research by linking persistence behavior over time to relapse-related outcomes for subjects prescribed natalizumab in a large commercially insured MS population in the United States. ${ }^{24,29}$

An interesting finding from this study comes from those that stayed in the same persistent group from the year prior to the year after treatment transitions. For example, for those who remained nonpersistent in the year prior and after transition, there was a small but significant downward trend in mean relapses. In contrast, for those who remained persistent in the year prior and after transition, there was a small nonsignificant downward change in relapses. These changes must be taken in context with the relapse rates in the year prior to treatment transition. That is, the nonpersistent subjects began at a much higher mean annualized relapse rate compared with the persistent subjects in the year prior to treatment transition $(0.67$ vs. 0.28). This suggests that those subjects who did switch or discontinue natalizumab were on some other treatment or best supportive care to reduce an already clinically high annualized relapse rate. Furthermore, some of these subjects did have natalizumab claims but were not persistent as defined in this study.

The treatment pattern results presented in this study are similar to previous research on persistence and discontinuation related to natalizumab. ${ }^{18}$ Bonafede et al. (2013) also used a large administrative claims database to analyze treatment patterns for commercially insured MS subjects prescribed platform therapies (e.g., IFNs) or natalizumab. ${ }^{18}$ The authors found that $13.9 \%$ of natalizumab users had a first switch and $9 \%$ discontinued during the 2 years after natalizumab initiation. This is similar to what is observed in our study where $22.9 \%$ who were persistent in the year prior to treatment transition were nonpersistent in the year after treatment transition. Our study adds to the previous work done by Bonafede et al. ${ }^{18}$ by linking treatment patterns to relapse outcomes.

Bergvall et al. (2014) used the PharMetrics Plus database to estimate persistence and differences in health care resource utilization after a switch to natalizumab or fingolimod. ${ }^{24}$ We found similar persistence percentages after initiation of natalizumab. In our study, we found that approximately $75 \%$ of subjects were persistent in the year after initiation of natalizumab; Bergvall et al. found persistence on natalizumab was approximately $76 \%$ the year after initiation. ${ }^{24}$ The authors also found significant reductions in relapses in the 12 months postinitiation of natalizumab compared with a pre-initiation 


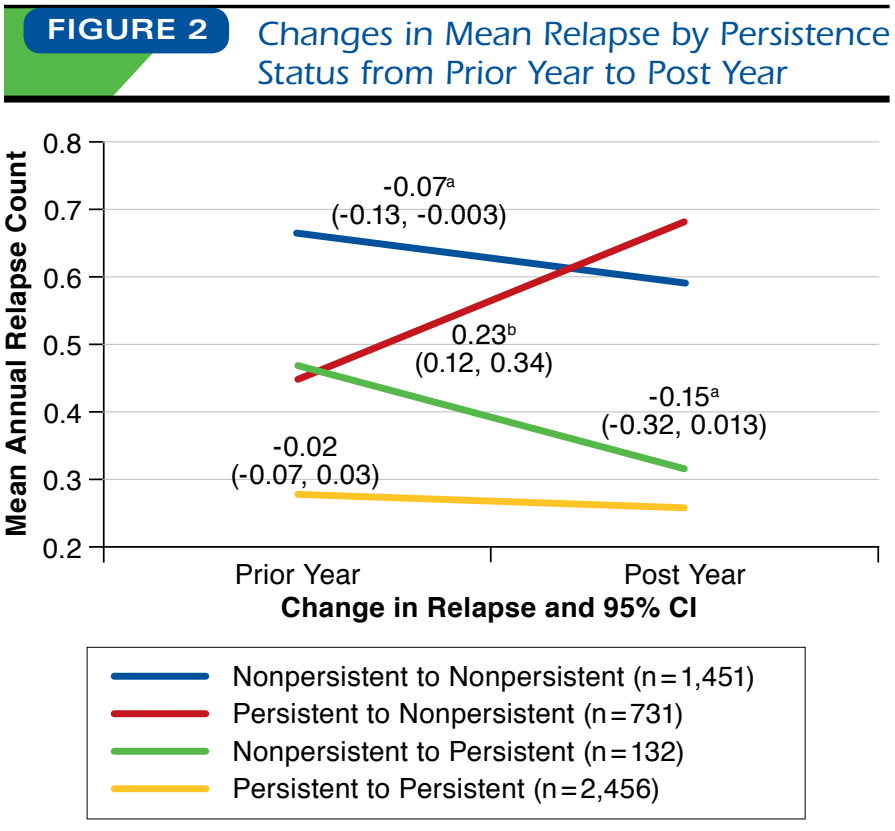

Note: $95 \%$ CI refers to within-group change in relapse uncertainty.

${ }^{a}$ Change significantly different at $P<0.10$ from reference group Persistent to Persistent. ${ }^{b}$ Change significantly different at $P<0.05$ from reference group Persistent to Persistent. $C I=$ confidence interval.

period using alternative DMTs. While there were similarities in treatment pattern results and relapse outcomes, our study design approach differs from Bergvall et al. ${ }^{24}$ We focused on a within-natalizumab group analysis with a longer follow-up period after initiation of natalizumab.

Our findings are consistent with previous observational studies suggesting a switch or discontinuation from other DMTs (e.g., IFNs or GA) is associated with a return in relapse activity. ${ }^{23,38}$ Reynolds et al. (2010) used PharMetrics PatientCentric Database to analyze health care resource utilization during an 18-month period after discontinuation or switch from an IFN or GA. ${ }^{23}$ The authors found that about half of patients remained on their index drugs. Of those that switched or discontinued, significantly higher health care utilization occurred during the 18-month follow-up period compared with those who were persistent on their original index drugs. Raimundo et al. (2013) conducted a subgroup analysis on switchers and discontinuers and found that high relapse activity predicts switching or discontinuing from DMTs among MS patients who had used a DMT previously. ${ }^{38}$ Our study adds to this research by correlating changes in persistence status with relapse outcomes for natalizumab specifically.

Moreover, the results are similar to previous studies suggesting a switch to natalizumab is associated with improvements in health for MS patients. ${ }^{13-15}$ Recently, Castillo-Trivino et al. (2011) conducted a retrospective cohort study at the University of California San Francisco MS Center to compare clinical

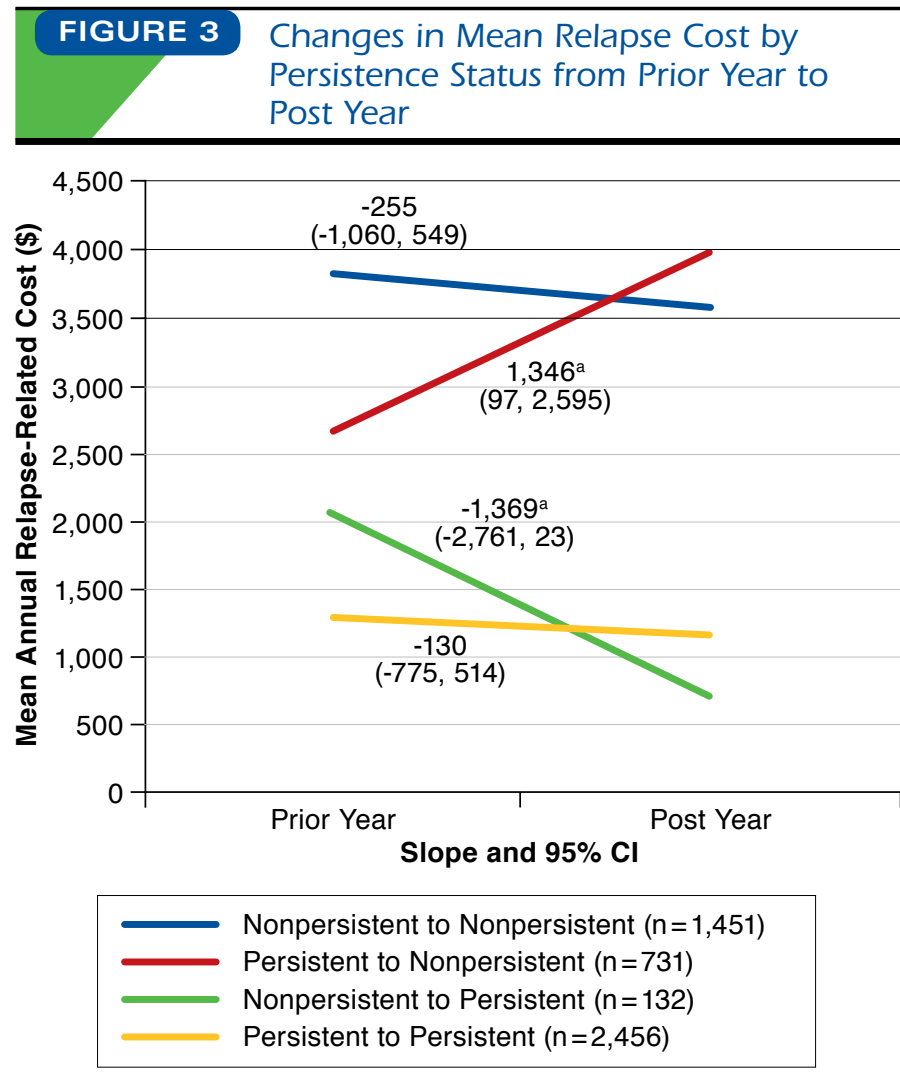

Note: $95 \%$ CI refers to within-group change in relapse uncertainty. Costs in 2012 U.S. dollars.

${ }^{a}$ Change significantly different at $P<0.05$ from reference group Persistent to Persistent. $C I=$ confidence interval.

effects of switching to natalizumab from first-line therapies. ${ }^{13}$ The authors found a significant and clinically meaningful $70 \%$ (95\% CI $=50 \%, 82 \%)$ reduction in the relapse rate for those switching from first-line DMTs to natalizumab. The study population was focused on MS patients experiencing breakthrough relapsing MS, even with prior DMT treatment. The patient selection in the present study may differ from Castillo-Trivino et al., since nearly $40 \%$ of the subjects were DMT treatment naive as of 1 year prior to natalizumab initiation. Lanzillo et al. (2013) estimated annualized relapse rates (ARR) in a group of MS patients who had been treated with natalizumab for at least 1 year after switching from a first-line DMT. ${ }^{14}$ They found a significant reduction in ARR within the natalizumab group and a statistically significant ARR between the group that stayed on first-line DMTs. Our results suggest that those who were persistent on natalizumab longer had fewer relapses and relapse-related costs than those who were not persistent.

Our relapse-related cost results differ from other studies because of our definition of relapse-related resource utilization. For example, O’Brien et al. (2003) split relapse care and 
subsequent health care utilization into 3 levels: high intensity management including hospitalization and follow-up care; medium level of intervention defined as a mix of emergency room visits, administration of acute treatments, or steroid burst in an outpatient setting; and lowest intensity of care including an outpatient visit with symptom-related medication prescriptions. ${ }^{39}$ Our estimates are in between the highest intensity treatment from O'Brien et al. (mean of $\$ 12,870$ in 2002 U.S. dollars) and closer to the medium level of care (mean of \$1,847). O'Brien et al. included additional resources such as skilled nursing facility use, home health care services, and rehabilitation services. We did not include these additional services in our definition of relapse-related costs. Our relapserelated cost estimates are closer to recent studies on natalizumab such as by Bonafede et al. (2013) ${ }^{29}$ that estimate relapse costs based on MS-specific resource utilization, along with the use of corticosteroids.

\section{Limitations}

The limitations of this analysis are similar to other claimsbased studies. ICD-9-CM diagnosis codes may have been miscoded. Misclassification bias was likely mitigated by our inclusion criteria (i.e., requiring an MS diagnosis prior to index date and initiation of natalizumab). The ICD-9-CM codes do not provide enough information to distinguish between relapsing-remitting and progressive forms of MS. Natalizumab is indicated for relapsing forms of MS; therefore, patients with progressive forms of MS may have a higher likelihood of nonpersistence with natalizumab. ${ }^{40}$ Patients with progressive forms of MS are known to have lower relapse rates on average than their RRMS counterparts. ${ }^{41}$ This limitation would potentially bias our results toward zero. Generalizability of this study limits the interpretation of the results to MS patients enrolled in commercial health plans in the United States.

Unfortunately, reasons for a subject being persistent or nonpersistent cannot be fully determined from administrative claims data. We were unable to observe important factors such as JC virus status, duration of disease, Expanded Disability Status Scale, and clinical markers, which could have provided key variables for adjustment at the analysis phase. In an attempt to address these limitations, we extracted measures of severity using ICD-9-CM diagnosis codes for MS-related symptoms and CPT-4 codes for movement aids. Despite these limitations, there were few significant differences between persistent and nonpersistent individuals in the first year after initiation of natalizumab. One difference, prior DMT use, was included in the multivariable analysis as a control variable.

Since relapse rates were annualized, we were not able to capture the distribution of relapses during each year. Previous studies have suggested a return in disease activity in subsets of patients specific to the first 3-7 months postdiscontinuation from natalizumab. ${ }^{11,42,43}$ The timing effect for the return in disease activity after discontinuing natalizumab should be further evaluated. Additionally, the timing of a relapse could impact the persistence status of subjects in this study; therefore, a causal relationship between persistence and relapse activity cannot be established.

Switching and discontinuing therapies are not necessarily considered nonpersistent behavior. Rather, switching is often a physician and patient choice due to a number of reasons. Similarly, discontinuation could happen because of adverse events. For the reasons stated previously, this limitation is somewhat mitigated by the objective of the analysis to compare the impact of using natalizumab consistently with inconsistent natalizumab use. It will be important for future studies to address this limitation with larger sample sizes if multiple treatment options are included to estimate the impact of treatment patterns on relapse-related outcomes.

\section{Conclusions}

The results of this study suggest that real-world persistent natalizumab users who become nonpersistent have meaningful and statistically significant increases in annual relapses and relapse-related costs. Those who transition from nonpersistent to persistent have nonsignificant reductions in relapses and their associated costs.

\section{Authors}

R. BRETT MCQUEEN, PhD, is Postdoctoral Fellow; KAVITA NAIR, PhD, is Professor; and JONATHAN D. CAMPBELL, PhD, is Assistant Professor, Department of Clinical Pharmacy, University of Colorado Skaggs School of Pharmacy and Pharmaceutical Sciences, University of Colorado Anschutz Medical Campus, Aurora. TERRIE LIVINGSTON, PharmD, is Senior Director, US Medical, and BRIEANA BUCKLEY, PharmD, is Associate Director, Value Based Outcomes, Biogen Idec, Weston, Massachusetts. TIMOTHY VOLLMER, MD, is Professor, and JOHN CORBOY, MD, is Professor, Department of Neurology, University of Colorado School of Medicine, Aurora. RICHARD READ ALLEN, MS, is Owner and CEO, Peak Statistical Services, Evergreen, Colorado.

AUTHOR CORRESPONDENCE: R. Brett McQueen, PhD, Postdoctoral Fellow, Department of Clinical Pharmacy, University of Colorado Skaggs School of Pharmacy and Pharmaceutical Sciences, Anschutz Medical Campus, Mail Stop C238, 12850 E. Montview Blvd., Aurora, CO 80045. Tel.: 303.709.9264; FAX: 303.724.0979; E-mail: Robert.mcqueen@ucdenver.edu.

\section{DISCLOSURES}

This study was supported by an investigator-initiated grant from Biogen Idec to the University of Colorado. The content is solely the responsibility of the authors. McQueen was supported by a postdoctoral grant from the PhRMA Foundation.

Study concept and design were conducted primarily by McQueen and Campbell with assistance from Livingston, Vollmer, Corboy, Buckley, Allen, and Nair. Programming of the data was done primarily by Allen with assistance from McQueen and Campbell. Data analysis was performed by McQueen, Campbell, and Allen. The manuscript was written by McQueen and Campbell and revised by Livingston, Vollmer, Corboy, Buckley, and Nair. 


\section{REFERENCES}

1. Campbell JD, Ghushchyan V, Brett McQueen R, et al. Burden of multiple sclerosis on direct, indirect costs and quality of life: national U.S. estimates. Mult Scler Relat Disord. 2014;3(2):227-36.

2. Compston A, Coles A. Multiple sclerosis. Lancet. 2002;359(9313):1221-31.

3. National Multiple Sclerosis Society. Types of MS. Available at: http://www nationalmssociety.org/What-is-MS/Types-of-MS. Accessed January 15, 2015 4. Scalfari A, Neuhaus A, Daumer M, Muraro PA, Ebers GC. Onset of secondary progressive phase and long-term evolution of multiple sclerosis. J Neurol Neurosurg Psychiatry. 2014;85(1):67-75.

5. Weinstock-Guttman B. An update on new and emerging therapies for relapsing-remitting multiple sclerosis. Am J Manag Care. 2013;19(17 Suppl): S343-54.

6. Devonshire V, Lapierre Y, Macdonell R, et al. The Global Adherence Project (GAP): a multicenter observational study on adherence to diseasemodifying therapies in patients with relapsing-remitting multiple sclerosis. Eur J Neurol. 2011;18(1):69-77.

7. Beer K, Müller M, Hew-Winzeler AM, et al. The prevalence of injectionsite reactions with disease-modifying therapies and their effect on adherence in patients with multiple sclerosis: an observational study. BMC Neurol. 2011;11:144.

8. Fox RJ, Salter AR, Tyry T, et al. Treatment discontinuation and disease progression with injectable disease-modifying therapies: findings from the North American research committee on multiple sclerosis database. Int J MS Care. 2013;15(4):194-201.

9. Cramer JA, Roy A, Burrell A, et al. Medication compliance and persistence: terminology and definitions. Value Health. 2008;11(1):44-47.

10. Tysabri (natalizumab) injection, for intravenous use. Biogen Idec, Inc. Revised January 2012. Available at: http://www.accessdata.fda.gov/drugsatfda_docs/label/2012/125104s0576lbl.pdf. Accessed January 15, 2015.

11. O'Connor PW, Goodman A, Kappos L, et al. Disease activity return during natalizumab treatment interruption in patients with multiple sclerosis. Neurology. 2011;76(22):1858-65.

12. Havla J, Gerdes LA, Meinl I, et al. De-escalation from natalizumab in multiple sclerosis: recurrence of disease activity despite switching to glatiramer acetate. J Neurol. 2011;258(9):1665-69.

13. Castillo-Trivino T, Mowry EM, Gajofatto A, et al. Switching multiple sclerosis patients with breakthrough disease to second-line therapy. PloS One. 2011;6(2):e16664

14. Lanzillo R, Bonavita S, Quarantelli M, et al. Natalizumab is effective in multiple sclerosis patients switching from other disease modifying therapies in clinical practice. Neurol Sci. 2013;34(4):521-28.

15. Prosperini L, Gianni C, Leonardi L, et al. Escalation to natalizumab or switching among immunomodulators in relapsing multiple sclerosis. Mult Scler. 2012;18(1):64-71.

16. Reynolds MW, Stephen R, Seaman C, Rajagopalan K. Persistence and adherence to disease modifying drugs among patients with multiple sclerosis. Curr Med Res Opin. 2010;26(3):663-74.

17. Oleen-Burkey M, Cyhaniuk A, Swallow E. Treatment patterns in multiple sclerosis: administrative claims analysis over 10 years. J Med Econ. 2013;16(3):397-406.

18. Bonafede MM, Johnson BH, Wenten M, Watson C. Treatment patterns in disease-modifying therapy for patients with multiple sclerosis in the United States. Clin Ther. 2013;35(10):1501-12.

19. Kleinman NL, Beren IA, Rajagopalan K, Brook RA. Medication adherence with disease modifying treatments for multiple sclerosis among U.S. employees. J Med Econ. 2010;13(4):633-40.

20. Agashivala N, Wu N, Abouzaid S, et al. Compliance to fingolimod and other disease modifying treatments in multiple sclerosis patients, a retrospective cohort study. BMC Neurol. 2013;13:138.

21. Bergvall N, Makin C, Lahoz R, et al. Relapse rates in patients with multiple sclerosis switching from interferon to fingolimod or glatiramer acetate: a US claims database study. PloS One. 2014;9(2):e88472.

22. Gajofatto A, Bacchetti P, Grimes B, High A, Waubant E. Switching firstline disease-modifying therapy after failure: impact on the course of relapsing-remitting multiple sclerosis. Mult Scler. 2009;15(1):50-58.

23. Reynolds MW, Stephen R, Seaman C, Rajagopalan K. Healthcare

resource utilization following switch or discontinuation in multiple sclerosis patients on disease modifying drugs. J Med Econ. 2010;13(1):90-98.
24. Bergvall N, Lahoz R, Reynolds T, Korn JR. Healthcare resource use and relapses with fingolimod versus natalizumab for treating multiple sclerosis: a retrospective US claims database analysis. Curr Med Res Opin. 2014;30(8):1461-71.

25. Bergvall N, Petrilla AA, Karkare SU, et al. Persistence with and adherence to fingolimod compared with other disease-modifying therapies for the treatment of multiple sclerosis: a retrospective U.S. claims database analysis J Med Econ. 2014;17(10):696-707.

26. Ivanova JI, Bergman RE, Birnbaum HG, Phillips AL, Stewart M, Meletiche DM. Impact of medication adherence to disease-modifying drugs on severe relapse, and direct and indirect costs among employees with multiple sclerosis in the U.S. J Med Econ. 2012;15(3):601-09.

27. Kozma CM, Phillips AL, Meletiche DM. Use of an early disease-modifying drug adherence measure to predict future adherence in patients with multiple sclerosis. J Manag Care Spec Pharm. 2014;20(8):800-07. Available at: http://www.amcp.org/WorkArea/DownloadAsset.aspx?id=18369.

28. Steinberg SC, Faris RJ, Chang CF, Chan A, Tankersley MA. Impact of adherence to interferons in the treatment of multiple sclerosis: a non-experimental, retrospective, cohort study. Clin Drug Investig. 2010;30(2):89-100.

29. Bonafede MM, Johnson BH, Watson C. Health care-resource utilization before and after natalizumab initiation in multiple sclerosis patients in the U.S. Clinicoecon Outcomes Res. 2013;6:11-20.

30. Charlson ME, Pompei P, Ales KL, MacKenzie CR. A new method of classifying prognostic comorbidity in longitudinal studies: development and validation. J Chronic Dis. 1987;40(5):373-83.

31. Deyo RA, Cherkin DC, Ciol MA. Adapting a clinical comorbidity index for use with ICD-9-CM administrative databases. J Clin Epidemiol. 1992;45(6):613-19.

32. Quan H, Sundararajan V, Halfon P, et al. Coding algorithms for defining comorbidities in ICD-9-CM and ICD-10 administrative data. Med Care. 2005;43(11):1130-39

33. Curkendall SM, Wang C, Johnson BH, et al. Potential health care cost savings associated with early treatment of multiple sclerosis using diseasemodifying therapy. Clin Ther. 2011;33(7):914-25.

34. Chastek BJ, Oleen-Burkey M, Lopez-Bresnahan MV. Medical chart validation of an algorithm for identifying multiple sclerosis relapse in healthcare claims. J Med Econ. 2010;13(4):618-25.

35. Ollendorf DA, Jilinskaia E, Oleen-Burkey M. Clinical and economic impact of glatiramer acetate versus beta interferon therapy among patients with multiple sclerosis in a managed care population. J Manag Care Spec Pharm. 2002;8(6):469-76. Available at: http://www.amcp.org/data/jmcp/ Research-469-476.pdf.

36. Cameron AC, Trivedi PK. Microeconometrics Using Stata. College Station, TX: Stata Press; 2009.

37. Cameron AC, Trivedi PK. Microeconometrics: Methods and Applications. Cambridge University Press; 2005.

38. Raimundo K, Tian H, Zhou H, et al. Resource utilization, costs and treatment patterns of switching and discontinuing treatment of MS patients with high relapse activity. BMC Health Serv Res. 2013;13:131.

39. O'Brien JA, Ward AJ, Patrick AR, Caro J. Cost of managing an episode of relapse in multiple sclerosis in the United States. BMC Health Serv Res. 2003;3(1):17.

40. Rudick R, Polman C, Clifford D, Miller D, Steinman L. Natalizumab: bench to bedside and beyond. JAMA Neurol. 2013;70(2):172-82.

41. Ebers GC. Natural history of multiple sclerosis. J Neurol Neurosurg Psychiatry. 2001;71(Suppl 2):iil6-19.

42. Sorensen PS, Koch-Henriksen N, Petersen T, Ravnborg M, Oturai A, Sellebjerg F. Recurrence or rebound of clinical relapses after discontinuation of natalizumab therapy in highly active MS patients. J Neurol. 2014;261(6):1170-77.

43. Jokubaitis VG, Li V, Kalincik T, et al. Fingolimod after natalizumab and the risk of short-term relapse. Neurology. 2014;82(14):1204-11. 


\begin{tabular}{|c|c|c|c|c|c|c|c|c|c|c|c|}
\hline & \multicolumn{2}{|c|}{$\begin{array}{c}\text { All } \\
\text { Nonpersistent in } \\
\text { Initiation Year }\end{array}$} & \multicolumn{3}{|c|}{$\begin{array}{c}\text { Switch in } \\
\text { Initiation Year }\end{array}$} & \multicolumn{3}{|c|}{$\begin{array}{l}\text { Discontinue in } \\
\text { Initiation Year }\end{array}$} & \multicolumn{3}{|c|}{$\begin{array}{l}\text { Did Not Switch or } \\
\text { Discontinue but } \\
\text { Nonpersistent in } \\
\text { Initiation Year }\end{array}$} \\
\hline & $\mathrm{N}$ & $\%$ & $\mathrm{~N}$ & $\%$ & $P$ Value $^{\mathrm{a}}$ & $\mathrm{N}$ & $\%$ & $P$ Value $^{\mathrm{a}}$ & $\mathrm{N}$ & $\%$ & $P$ Value $^{\mathrm{a}}$ \\
\hline Total & 607 & - & 174 & 29.00 & & 347 & 57.00 & & 86 & 14.00 & \\
\hline Gender & & & & & 0.552 & & & 0.820 & & & 0.274 \\
\hline Male & 171 & 28.17 & 52 & 29.89 & & 99 & 28.53 & & 20 & 23.26 & \\
\hline Female & 436 & 71.83 & 122 & 70.11 & & 248 & 71.47 & & 66 & 76.74 & \\
\hline Age group & & & & & 0.920 & & & 0.692 & & & 0.585 \\
\hline $0-35$ & 107 & 17.63 & 29 & 16.67 & & 65 & 18.73 & & 13 & 15.12 & \\
\hline $36-44$ & 187 & 30.81 & 57 & 32.76 & & 105 & 30.26 & & 25 & 29.07 & \\
\hline $45-54$ & 208 & 34.27 & 59 & 33.91 & & 114 & 32.85 & & 35 & 40.70 & \\
\hline $55+$ & 105 & 17.30 & 29 & 16.67 & & 63 & 18.16 & & 13 & 15.12 & \\
\hline Payer type & & & & & 0.184 & & & 0.290 & & & 0.767 \\
\hline Commercial & 369 & 60.79 & 116 & 66.67 & & 203 & 58.50 & & 50 & 58.14 & \\
\hline Medicaid or Medicare & 13 & 2.14 & 0 & 0.00 & & 11 & 3.17 & & 2 & 2.33 & \\
\hline Self-insured & 225 & 37.07 & 58 & 33.33 & & 133 & 38.33 & & 34 & 39.53 & \\
\hline Insurance type & & & & & 0.137 & & & 0.594 & & & 0.155 \\
\hline Health maintenance organization & 75 & 12.36 & 26 & 14.94 & & 40 & 11.53 & & 9 & 10.47 & \\
\hline Indemnity & 25 & 4.12 & 11 & 6.32 & & 11 & 3.17 & & 3 & 3.49 & \\
\hline Preferred provider network & 449 & 73.97 & 125 & 71.84 & & 259 & 74.64 & & 65 & 75.58 & \\
\hline Point of service & 49 & 8.07 & 12 & 6.90 & & 32 & 9.22 & & 5 & 5.81 & \\
\hline Consumer driven & 4 & 0.66 & 0 & 0.00 & & 2 & 0.58 & & 2 & 2.33 & \\
\hline Unknown & 5 & 0.82 & 0 & 0.00 & & 3 & 0.86 & & 2 & 2.33 & \\
\hline Region & & & & & 0.055 & & & 0.212 & & & 0.859 \\
\hline East & 186 & 30.64 & 63 & 36.21 & & 97 & 27.95 & & 26 & 30.23 & \\
\hline Midwest & 165 & 27.18 & 44 & 25.29 & & 99 & 28.53 & & 22 & 25.58 & \\
\hline South & 194 & 31.96 & 57 & 32.76 & & 110 & 31.70 & & 27 & 31.40 & \\
\hline West & 62 & 10.21 & 10 & 5.75 & & 41 & 11.82 & & 11 & 12.79 & \\
\hline \multicolumn{12}{|l|}{ MS-related symptoms ${ }^{b}$} \\
\hline Visual & 128 & 21.09 & 39 & 22.41 & 0.612 & 74 & 21.33 & 0.868 & 15 & 17.44 & 0.371 \\
\hline Movement disorders & 155 & 25.54 & 45 & 25.86 & 0.907 & 90 & 25.94 & 0.793 & 20 & 23.26 & 0.601 \\
\hline Facial neuralgia & 17 & 2.80 & 10 & 5.75 & 0.005 & 5 & 1.44 & 0.019 & 2 & 2.33 & 0.773 \\
\hline Dizziness & 63 & 10.38 & 22 & 12.64 & 0.246 & 30 & 8.65 & 0.106 & 11 & 12.79 & 0.429 \\
\hline Fatigue & 14 & 2.31 & 3 & 1.72 & 0.545 & 10 & 2.88 & 0.275 & 1 & 1.16 & 0.446 \\
\hline Paralysis & 27 & 4.45 & 7 & 4.02 & 0.747 & 18 & 5.19 & 0.307 & 2 & 2.33 & 0.303 \\
\hline Headache & 8 & 1.32 & 2 & 1.15 & 0.817 & 4 & 1.15 & 0.680 & 2 & 2.33 & 0.376 \\
\hline Muscle & 67 & 11.04 & 22 & 12.64 & 0.424 & 41 & 11.82 & 0.480 & 4 & 4.65 & 0.041 \\
\hline Speech & 11 & 1.81 & 4 & 2.30 & 0.569 & 7 & 2.02 & 0.662 & 0 & 0.00 & 0.174 \\
\hline Skin disturbance & 113 & 18.62 & 34 & 19.54 & 0.711 & 60 & 17.29 & 0.333 & 19 & 22.09 & 0.371 \\
\hline \multicolumn{12}{|l|}{ Movement aids $^{c}$} \\
\hline Walker & 16 & 2.64 & 7 & 4.02 & 0.176 & 9 & 2.59 & 0.940 & 0 & 0.00 & 0.100 \\
\hline Wheelchair & 21 & 3.46 & 8 & 4.60 & 0.331 & 13 & 3.75 & 0.655 & 0 & 0.00 & 0.058 \\
\hline Prior DMT use (yes)d & 315 & 51.89 & 136 & 78.16 & $<0.001$ & 148 & 42.65 & $<0.001$ & 31 & 36.05 & $<0.001$ \\
\hline Charlson Comorbidity Index (mean, SD) & 3.48 & 1.91 & 3.51 & 1.94 & 0.810 & 3.53 & 1.86 & 0.445 & 3.21 & 2.01 & 0.162 \\
\hline Relapse count & 0.62 & 1.27 & 0.76 & 1.16 & 0.079 & 0.54 & 1.12 & 0.108 & 0.62 & 1.88 & 0.999 \\
\hline \multicolumn{12}{|c|}{ 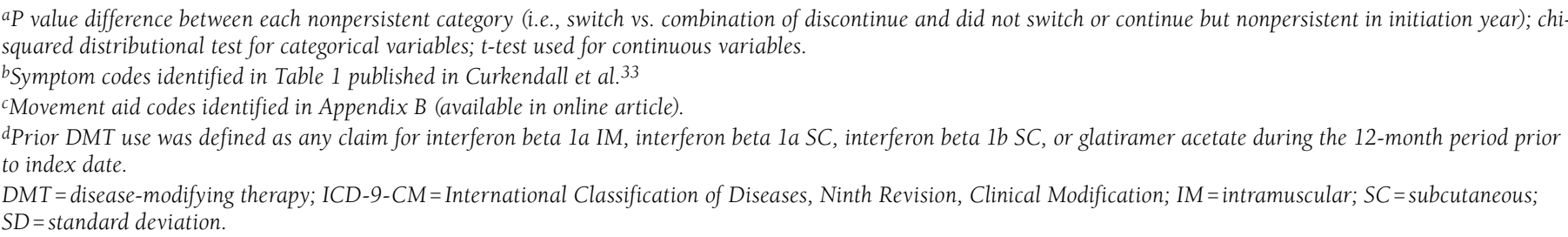 } \\
\hline
\end{tabular}




\begin{tabular}{|c|c|c|}
\hline APPENDIX B & \multicolumn{2}{|c|}{$\begin{array}{l}\text { CPT and HCPCS Codes Used } \\
\text { for Walking Aids }\end{array}$} \\
\hline Category & Code Type & Code \\
\hline \multirow{16}{*}{ Wheelchairs } & $\mathrm{CPT}$ & 97542 \\
\hline & HCPCS & E1140 \\
\hline & HCPCS & E1150 \\
\hline & HCPCS & E1260 \\
\hline & HCPCS & K0001 \\
\hline & HCPCS & E1088 \\
\hline & HCPCS & K0003 \\
\hline & HCPCS & K0004 \\
\hline & HCPCS & K0005 \\
\hline & HCPCS & K0006 \\
\hline & HCPCS & K0007 \\
\hline & HCPCS & K0008 \\
\hline & HCPCS & E1211 \\
\hline & HCPCS & E1212 \\
\hline & HCPCS & K0011 \\
\hline & HCPCS & K0014 \\
\hline Scooter & HCPCS & E1230 \\
\hline & HCPCS & E0130 \\
\hline & HCPCS & E0135 \\
\hline & HCPCS & E0140 \\
\hline & HCPCS & E0141 \\
\hline Walkers & HCPCS & E0143 \\
\hline & HCPCS & E0147 \\
\hline & HCPCS & E0148 \\
\hline & HCPCS & E0149 \\
\hline
\end{tabular}

